\title{
Neonatal Hyperbilirubinemia in Low-Income African Countries
}

\author{
Adam C Gamber ${ }^{1 *}$, Ethan M Toth ${ }^{1}$, Hendrik J Vreman' ${ }^{2}$ and Tina M Slusher, \\ ${ }^{1}$ The 450 Project, Asset Genie Inc., Greensburg, USA \\ ${ }^{2}$ Division of Neonatal and Developmental Medicine, Department of Pediatrics, Stanford University School of Medicine, USA \\ ${ }^{3}$ Pediatrics, University of Minnesota, USA \\ ${ }^{4}$ Hennepin Healthcare, Minneapolis, USA \\ *Corresponding author: Adam C Gamber, The 450 Project, Asset Genie Inc., Greensburg, PA 15601, \\ USA, Tel: 724-610-7559
}

\begin{abstract}
Neonatal hyperbilirubinemia, also known as jaundice, is a significant cause of neonate death and disability in low- and middle-income countries (LMICs). Lack of adequate healthcare facilities, unreliable diagnostic- and treatment equipment, limited parental knowledge, and inconsistent- or absent treatment protocols all contribute to exceptionally high rates of morbidity and mortality especially in Sub-Saharan Africa. This review summarizes the etiology and treatment of neonatal hyperbilirubinemia, delineates standard of care discrepancies between high-income countries and LMICs, and describes innovative technologies intended to treat neonatal jaundice in these low-resource areas. Filtered sunlight phototherapy (FSPT), using inexpensive window-tinting film, has been shown to provide safe and effective phototherapy treatment and has been shown to be non-inferior to conventional phototherapy devices. In addition, solar powered phototherapy is being developed and improved and other low-cost phototherapy is being developed. By working in partnership with our colleagues from LMICs to provide low-cost, reliable technologies, in combination with appropriate training and educational interventions, to their people in LMICs, the hope is that the gap in morbidity and mortality rates due to hyperbilirubinemia will diminish.
\end{abstract}

\section{Keywords}

Hyperbilirubinemia, Neonatal jaundice, Phototherapy, Filtered sunlight

\section{List of Abbreviations}

ABE: Acute Bilirubin Encephalopathy; AAP: American Academy of Pediatrics; FSPT: Filtered Sunlight Phototherapy; IR: Infrared; KSD: Kernicterus Spectrum Disorder; LED: Light Emitting Diode; LMICs: Low- and Middle-Income Countries; RBC: Red Blood Cell; SGA: Small For Gestational Age; TSB: Total Serum Bilirubin; TcB: Transcutaneous Bilirubinometer; UVA: Ultraviolet A; UV: Ultraviolet

\section{Background}

Neonatal jaundice is a common condition, often manifested through a visible yellowing of the skin, eyes, or other tissues [1]. Over $60 \%$ of all term, and $80 \%$ of all pre-term, neonates develop some form of neonatal jaundice [2]. The condition is typically benign, but can progress to severe hyperbilirubinemia leading to acute bilirubin encephalopathy (ABE) [3-5] and kernicterus spectrum disorder (KSD) [6].

Worldwide about 24 million neonates are born each year who are at risk of complications due to hyperbilirubinemia [5]. Although kernicterus is preventable with prompt treatment, it is estimated that at least 114,000 infants die every year from hyperbilirubinemia, and and more than 63,000 live with permanent neurological impairment [5]. As demonstrated in a systematic review and meta-analysis, the vast majority of the morbidity and mortality of severe hyperbilirubinemia occurs in the Sub-Saharan African- and South Asian regions [5]. The progressive sequalae are largely preventable if neonatal jaundice is promptly diagnosed and treated effectively [3].

Jaundice is caused by the presence in skin and eyes of unconjugated bilirubin, a yellow break down product of hemoglobin, derived from senescing red blood cells (RBC) $[7,8]$. Normally, unconjugated bilirubin binds to plasma albumin to be transported to the liver, where it is conjugated with one or two molecules of glucuronic acid, making it water-soluble. Bilirubin conjugates are then secreted into bile and eliminated from the body via the intestine [1].

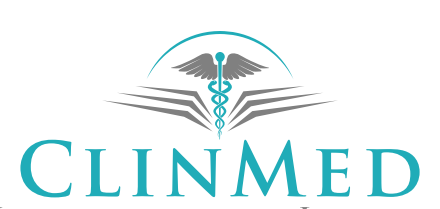

INTERNATIONAL LIBRARY
Citation: Gamber AC, Toth EM, Vreman HJ, Slusher TM (2021) Neonatal Hyperbilirubinemia in Low-Income African Countries. Int J Pediatr Res 7:073. doi.org/10.23937/2469-5769/1510073

Accepted: February 17, 2021: Published: February 19, 2021

Copyright: (c) 2021 Gamber AC, et al. This is an open-access article distributed under the terms of the Creative Commons Attribution License, which permits unrestricted use, distribution, and reproduction in any medium, provided the original author and source are credited. 
In healthy adults, intestinal bacteria reduce conjugated bilirubin into urobilin, which can then be excreted. Neonates have an immature bilirubin conjugation capacity and fewer gut bacteria and, therefore they cannot optimally reduce excess bilirubin into its harmless derivatives [7]. Additionally, neonates have high levels of an enzyme (beta-glucuronidase) that deconjugates bilirubin in the intestine back into unconjugated bilirubin, which can then be reabsorbed into the bloodstream, thereby adding to the bilirubin burden [1]. In most cases, after 10-14 days, the term neonate's body has adapted to post-partum life and is properly processing bilirubin and the bilirubin begins to decline [8]. At this point, the risk of neonatal hyperbilirubinemia decreases, except in cases of abnormal bilirubin production, such as hemolysis in neonates with G-6-PD deficiency, Rhesus and $A B O$ incompatibility, Crigler-Najjar Syndrome [9], or other pathologic conditions [10].

Additionally, any of the following can also contribute to elevated levels of bilirubin: Increased red blood cell (RBC) production and destruction, decreased hepatic (liver) uptake, decreased conjugation of bilirubin, impaired excretion, impaired bile flow, or increased enterohepatic circulation (reabsorption of bilirubin from the intestine into blood circulation) $[1,7]$.

Some clinicians still divide hyperbilirubinemia into two categories: physiologic and pathologic, and these have been terms used historically $[7,8,11]$. However, the exact definition or distinction between these two conditions is complex and complicated by many factors not limited to cause alone. Physiologic jaundice occurs in most healthy infants. Many factors lead to this including the increased hemoglobin levels in circulation in most neonates due to the need for increased oxygen carrying capacity in their relatively hypoxic intra-uterine life, shortened RBC life-span in neonates as compared to adults, and states leading to increased bilirubin production [7,8,11-13]. Other factors include deficiency in conjugating enzymes which may decrease bilirubin clearance and low gut bacteria levels combined with increased hydrolysis of conjugated bilirubin thus increasing reuptake via the liver and intestines $[7,8]$. In general, physiologic jaundice typically does not require medical intervention, does not occur in the first 24 hours of life, peaks at $\leq 12 \mathrm{mg} / \mathrm{dL}$ (although its level can sometimes rise as high at $18 \mathrm{mg} / \mathrm{dL}$ ), and resolves within one week [11]. However, clinicians must assume that "physiologic" jaundice can become severe or exaggerated, last longer than one week and that it might need treatment $[11,14]$. One important and common example of one type of jaundice that can be placed in the physiologic jaundice category is breast feeding jaundice which some now called starvation jaundice $[12,13]$. It generally responds to frequent feedings which promote passing stool to reduce reuptake of bilirubin in the intestines [1] and lactation support to improve latch and effective suck and occasionally supplementation. Supplementa- tion however is discouraged especially in LMICs, except when medically indicated, due to the risk of contamination and death or serious illness [15]. If supplementation or lactation support fail to bring the TSB into a safe range based on age and risk category and the neonate's clinical presentation, treatment including phototherapy and even exchange transfusion should be implemented.

Another type of jaundice associated with breast feeding is breast milk jaundice. The exact cause is still poorly understood but is believed to be due to factors in the breast milk itself [16]. When the TSB remains below $20 \mathrm{mg} / \mathrm{dL}$ in term healthy neonates, and other causes of hyperbilirubinemia have been ruled out no treatment is needed. However, if the TSB rises to 20 $\mathrm{mg} / \mathrm{dL}$ or greater many clinicians will interrupt breastfeeding briefly (generally for $\sim 24 \mathrm{hrs}$ ). If the jaundice is truly due to breast milk jaundice the bilirubin will be expected to plummet and breastfeeding should be resumed [16]. The challenge in this situation is to interrupt breast feeding briefly without making the mother feel as though her breast milk is "bad" and then be unwilling to resume breastfeeding. Again as stated above this is particularly problematic in LMICs where alternate feedings are often associated with illness and death of these neonates [15].

It may be more helpful to state the percentile of the total serum bilirubin (TSB) based on the neonates age (preferably maintaining TSB $>95 \%$ for age) rather than to call a particular value either physiologic or pathologic $[12,13]$. Severe or significant (sometimes called pathologic) hyperbilirubinemia in-term and near-term neonates ( $>38$ weeks gestation) is diagnosed if $[8,12,13,17]$ :

- Jaundice appears within the first 24 hours of life or lasts for > two weeks

- TSB rises at an exceptionally fast rate of $>5 \mathrm{mg} / \mathrm{dL} /$ day, or $>0.2 \mathrm{mg} / \mathrm{dL} / \mathrm{hr}$ ( $>85.5 \mu \mathrm{mol} / \mathrm{L} /$ day, or $>3.42$ $\mu \mathrm{mol} / \mathrm{L} /$ day)

- TSB measured at $>18 \mathrm{mg} / \mathrm{dL}$ any time or above $95 \%$ for age in the population

- Infant shows symptoms of moderate-severe ABE

Plasma/serum bilirubin levels are not universal markers for all infants as alluded to above. Particularly for premature, ill, or small for gestational age (SGA) infants, TSB concentrations can reach potentially dangerous levels well below $18 \mathrm{mg} / \mathrm{dL}$ [1]. In addition to prematurity, risk factors which place the neonates at higher risk for $A B E / K S D$ include a multitude of factors as noted by the AAP including "isoimmune hemolytic disease, G6PD deficiency, asphyxia, significant lethargy, sepsis, acidosis, or an albumin level <3.0g/L" [17]. History should include any siblings needing treatment for jaundice, maternal history, race or ethnicity, occupation, maternal diabetes, and maternal age $[17,18]$. Physical exam should note presence of jaundice and degree of progression, plethora, size, temperature (or 
history of hypothermia or fever), presence of bruising or cephalohematoma, dysmorphic features, evidence of hepatomegaly, intestinal obstruction or tone abnormalities $[1,8,17,18]$.

TSB concentrations $>10 \mathrm{mg} / \mathrm{dL}(171 \mu \mathrm{mol} / \mathrm{L})$ in preterm infants [1] and above $95 \%$ for age in the population in all neonates, regardless of their gestational age, require additional testing and/or treatment $[12,13,17]$. Direct (conjugated) bilirubin is more than $1 \mathrm{mg} / \mathrm{dL}$ (17.1 $\mu \mathrm{mol} / \mathrm{L}$ ) when total bilirubin concentration is under 5 $\mathrm{mg} / \mathrm{dL}(85.5 \mu \mathrm{mol} / \mathrm{L})$ or if conjugated bilirubin level is over $20 \%$ of TSB if TSB is $>5 \mathrm{mg} / \mathrm{dL}$ [11]. This type of hyperbilirubinemia generally requires a definite workup and treatment and will not be discussed in detail in this article.

Work-up for hyperbilirubinemia requiring treatment should generally include blood type of the mother and infant, including Rh factor, G6PD testing especially in any area with a risk of $>5 \%$ in males, complete blood count with a peripheral smear, Coombs testing, reticulocyte count and at least one direct bilirubin level [11].

While clinicians are good at determining if jaundice is present or absent, they are not skilled at determining the exact TSB $[19,20]$. However, in LMICs, using the Kramer scale which relies on the cephalad to caudad progression of jaundice, has been shown to be helpful in determining whether the TSB is $\geq 15 \mathrm{mg} / \mathrm{dL}$ [21]. Additionally, any infant with jaundice on the first day of life or jaundice of the eyes, palms of hands or soles of feet should have a TSB done. Clinical exam for jaundice is best done in bright daylight [8].

The main concern of hyperbilirubinemia is bilirubin's role as a neurotoxin; at high concentrations, unbound bilirubin can cause neurological impairments, $A B E$ in the first weeks of life and KSD beyond the neonate which can include deafness, choreoathetoid cerebral palsy, or even death $[6,23]$. ABE and KSD are believed to be caused by unbound bilirubin crossing the blood brain barrier and depositing in the basal ganglia or brain stem. Unconjugated bilirubin exists in both bound and unbound forms with the unbound or free bilirubin [23] likely causing the toxicity.

The level of hyperbilirubinemia is frequently estimated using a handheld transcutaneous bilirubinometer $(\mathrm{TCB})$ that provides an estimate of the intensity of jaundice [24]. An ideal device that works well for all levels of TSB and across all ethnicities and groups of infants has yet to be developed. Some TcB brands and models have been found to overestimate TSB and others underestimate it [25]. However, several studies have demonstrated their usefulness as screening tools [26-28].

\section{Standard Treatment of Hyperbilirubinemia}

The treatment of neonatal jaundice is a well-established practice in high income countries $[1,3,4,29]$.
Blue-light phototherapy is the standard of care for neonatal hyperbilirubinemia $[1,30]$. Phototherapy uses light within the wavelength range of $400-520 \mathrm{~nm}$ with a peak around 460-480 [17,31] to photoisomerize unconjugated bilirubin into more water-soluble forms that can be excreted rapidly by the liver and kidneys [32]. The minimum intensity (irradiance) for conventional and intensive phototherapy recommended to $\geq 8-10 \mu \mathrm{W} /$ $\mathrm{cm}^{2} / \mathrm{nm}$ and $\geq 30 \mu \mathrm{W} / \mathrm{cm}^{2} / \mathrm{nm}$, respectively [17]. However, higher irradiance levels (up to $100 \mu \mathrm{W} / \mathrm{cm}^{2} / \mathrm{nm}$ ) are required for the nightly treatment of Crigler-Najjar I patients [9]. Historically, phototherapy has been considered to be benign. But concerns, especially in the extremely low birth weight neonates, increasingly point to the need to treat phototherapy as we would any other drug and titrate phototherapy irradiance to the risk category and clinical status of the individual neonate [30].

Thresholds for initiating phototherapy are dependent on the gestational and postnatal age of the infant. In general, infants with a lower gestational or postnatal age have lower initiation thresholds [1,11,17]. A nomogram outlining the threshold levels at which various treatments should begin in a specific clinical environment has been developed by VK Bhutani, et al. at Stanford University [17]. However, this chart should only serve as a guide for countries to develop their own country- or even region specific guidelines. Localized guidelines should be developed based on risk categories, treatment options, and challenges that are country and region-specific. Using generic guidelines in LMICs without appropriate adaptations may lead to more $\mathrm{ABE} / \mathrm{KSD}$.

During phototherapy treatment, visible jaundice can disappear even though plasma bilirubin levels remain elevated, so neither visual examination of skin color nor transcutaneous bilirubin measurements (unless areas have been shielded) should routinely be used to evaluate hyperbilirubinemia severity after phototherapy has begun [1,30]. Incidentally, any blood taken for testing during phototherapy should be shielded from light with opaque containers to prevent pre-analytical photo-alteration of the sample and inaccuracies in measurement [1].

Exchange transfusions are rarely performed in high income countries as noted in a large study from California [33] and this is likely due in large part to availability of effective phototherapy. This is not the case in LMICs [4], where much of the phototherapy has not been shown to therapeutic [34-37]. If phototherapy fails to slow the rise of TSB levels sufficiently, or if TSB levels reach exchange levels, an exchange transfusion should be considered but exact levels will need to be based on country specific guidelines [17,38,39]. Additionally, exchange transfusions should be done in any neonate with moderate-severe $A B E$, regardless of the TSB level [17]. 
There are several risks associated with exchange transfusions, including infections, use of inappropriate blood, apnea, bradycardia (slow heartbeat), cyanosis (blue tint to extremities caused by low blood oxygen levels), vasospasm (blood vessel contractions), blood clots, and necrotizing enterocolitis (bowel disintegration), electrolyte abnormalities and even death [40]. These occurrences are believed to be uncommon although there is limited documentation of these complications from LMICs where most exchange transfusions currently occur $[39,41,42]$. Medical staff performing exchange transfusions should remain mindful of such preventable adverse effects and monitor neonates closely throughout and following an exchange.

\section{Outcomes in Low-income Countries}

The Sub-Saharan African and South Asian regions bear the majority of the world's burden of severe hyperbilirubinemia. In fact, neonatal hyperbilirubinemia is the seventh and eighth leading cause of early neonatal-period (i.e., 0-6 days) infant mortality in Sub-Saharan Africa and South Asia, respectively [43]. Reliable statistics are difficult to gather, but it is estimated and accepted that the rates of hyperbilirubinemia in these regions far surpass those in high-income countries $[3,4]$.

For example, severe neonatal hyperbilirubinemia incidence in Europe and the Americas is estimated to be between $3.2 / 10,000$ and $4.4 / 10,000$ live births, respectively, while its incidence in Southeast Asian and African countries is estimated to be $251.3 / 10,000$ and $667.8 / 10,000$ live births, respectively [4]. In high-income countries, the prevalence for kernicterus is reported as $10 / 100,000$ live births, but in Eastern Europe/Central Asia, Latin America, Sub-Saharan Africa, and South Asia, it is reported at $73 / 100,000$ live births [3].

The harmful sequalae of neonatal hyperbilirubinemia are well known. Less known are the systemic clinical, political, sociocultural, and economic interactions that underlie the health care system constraints that contribute to regional differences of disease burden [44].

\section{Morbidity and Mortality Factors}

One of the largest factors contributing to excessively high rates of neonatal hyperbilirubinemia in LMICs is the low rate of hospital births [43]. In these countries, a significant percentage of births occur outside of hospitals, thereby burdening mothers and families with recognizing jaundice on their own [43]. As noted above, visual evaluation of jaundice can be insufficient in properly diagnosing hyperbilirubinemia and is especially unreliable in determining severity $[19,20]$. To compound the issue, jaundice is more difficult to visually detect in infants with pigmented skin [45]. These factors make at-home detection of jaundice difficult, and lead to the vast majority of cases of severe neonatal jaundice oc- curring outside hospital settings [28].

Delays in treatment contribute significantly to the morbidity rates in LMICs [29]. Supportive evidence for delays comes, in part, in the form of higher rates of adverse clinical outcomes in infants within these regions [4]. Although a crash cart approach to the treatment of severe neonatal hyperbilirubinemia and even $A B E$ have been shown to reduce serious outcomes [30] there appears to be a point at which KSD is no longer reversible. Neonates with a BIND score of $<4$ are felt to be reversible and some of those with a BIND score of 4-6 maybe reversible with treatment [46].

As noted by Olusanya, et al. [29], delays occur for many reasons including delays in seeking care because of lack of recognition, knowledge, and appropriate treatment of the problem by both caregivers and healthcare providers, finances, and distance on the part of the caregivers. As pointed out in this article, sadly care often only happens when the child has signs of ABE [29]. Healthcare providers sometimes recommend suboptimal or ineffective treatment including unfiltered sunlight, herbs, glucose, and antibiotics $[29,47,48]$. Prenatal screening does not always screen for potential blood group incompatibilities or set-up for Rhesus isoimmunization and even when they do effective prophylaxis maybe unavailable or unaffordable [49].

Yet another type of delay noted in the article by Olusanya, et al. [29] are the multifaceted problem of less than optimal jaundice-specific care at the healthcare facility due to lack of necessary guidelines, diagnostic tests, screening tests such as G6PD, and the ability monitor bilirubin appropriately. As mentioned above, all of these problems are also often associated with ineffective phototherapy $[29,34-37,50]$.

In addition to delays, infections (particularly umbilical sepsis caused by improper measures of severing the umbilical cord), handling the neonate with unsterilized materials, and delivery in an unhygienic environment, were common outside hospital settings [51]. All of these factors increase the risk of severe hyperbilirubinemia.

This suboptimal treatment contributes to wasted time, resources a high rate of exchange transfusion and their associated risks in LMICs. Improper installation and maintenance of phototherapy devices also contributes to low treatment quality [35]. It was demonstrated that simple distance to skin adjustments and normal maintenance on phototherapy devices in Nigeria could elevate average irradiance values from below the minimum level for conventional phototherapy $(<10 \mu \mathrm{W} /$ $\left.\mathrm{cm}^{2} / \mathrm{nm}\right)$ to nearly intensive phototherapy levels $(27.3$ $\mu \mathrm{W} / \mathrm{cm}^{2} / \mathrm{nm}$ ) [35].

Publications of follow-up of children with KSD in LMICs suggest that the children who survive suffer from a host of problems including choreo-athetoid cerebral palsy, deafness, and auditory processing disorders 
[52-55]. Long-term follow-up is challenging and the resources needed to meet their ongoing needs are limited $[56,57]$.

\section{Advances in Light Sources for PT}

For several decades after its first implementation, the technology of phototherapy remained stagnant due to its dependence on the relatively slow advancement of basic interior lighting technology [58]. Fluorescent tubes and compact bulbs as well as halogen lamps remained the standard of care for phototherapy despite issues with high temperatures, UV light emission, and inefficient energy output in the therapeutic wavelength range [58-60].

However, ever since the discovery and development of gallium nitride light emitting diodes (LED) in the early 1990 's, this solid state light-emitting technology has expanded the original limited delivery of yellow and red light to now include the blue and green spectral emission $[61,62]$. Further technological and manufacturing advancements have led to the present availability of full spectrum LED light, including white light, opening up many new options for novel applications [63].

In recent years, LED technology has been demonstrated to be a more suitable alternative to fluorescentand halogen-lamp technology for the phototherapeutic treatment of hyperbilirubinemia $[9,64,65]$. Advantages of LED lamps include: Physical ruggedness, longer lifespan (> 20,000 hours), lower heat output, no UV generation, low cost, as well as low cost of operation. Furthermore, the selectable narrow spectral emission ( $25 \mathrm{~nm}$ ) as well as a range of selectable peak intensities, allow for the production of phototherapy devices that deliver blue light of quality and intensity that are superior to fluorescent- and tungsten-lamp based devices $[63,66]$. When using LED technology to treat neonates, rates of TSB decline are typically higher and incidences of hyperthermia are lower $[60,67]$. Especially in low-resource settings, where durability, longevity, and efficiency of equipment is vital to building and maintaining a standard of care, the use of LED technology is strongly recommended [64].

\section{New Treatment Devices}

During the past decade, a number of companies, organizations, and individuals have begun to take steps to produce inexpensive and durable phototherapy devices locally, with local labor and supplies [68]. Diagnostic tools and protocols are being developed and produced in areas of need and need to be accompanied by the necessary training $[18,69,70]$.

Little Sparrows Technologies in Boston, Massachusetts has developed a collapsible bassinet and LED-lined canopy to provide portable phototherapy [71]. This device meets the American Academy of Pediatrics (AAP) requirements for high-intensity phototherapy and has been proven effective in field trials in Peru [72]. D-Rev's Brilliance line of LED-based phototherapy devices are designed for use in low-resource settings and are manufactured by Phoenix Medical Systems Private LTD, Chennai, India. Utilized worldwide, the Brilliance devices have treated over 600,000 infants (of whom 500,000 would have otherwise had no access to treatment) since 2012 [73]. Massachusetts-based Design that Matters has created the LED-based Firefly, a rugged and virtually surround phototherapy device designed for low-resource settings and inexperienced staff. It is presented as "hard to use wrong" and has treated over 200,000 infants as of 2018 [74].

Researchers at Rice University (Houston, Texas) have developed the BiliSpec, a whole-blood compatible diagnostic device that reads TSB concentrations quickly, accurately, and cheaply [45]. Tiny Hearts, a Lagos Nigeria organization, founded by Virtue Oboro, produces the "Crib Aglow", a collapsible phototherapy hut designed for use in low-resource hospitals in urban- and rural areas [75].

\section{Filtered Sunlight Phototherapy}

Sunlight has been shown to be effective at rapidly decreasing bilirubin levels $[76,77]$. Sunlight formed the foundation for modern electric powered phototherapy when first tested by Cremer in the 1950's in England. It was later tested in Nigeria by Olowe and reported in 1985 [78]. Sunlight contains as much as $\geq 120 \mu \mathrm{W} /$ $\mathrm{cm}^{2} / \mathrm{nm}$ blue light of $400-520 \mathrm{~nm}$ (measured with the BiliBlanket Meter II between the hours of 1000-1600 $\mathrm{hr}$ under a cloudless sky) the wavelength band that is considered optimal for the photoisomerization of bilirubin [79]. The negative effects of sunlight are associated with both ultraviolet (UV) of 100-400 nm (i.e., risk of sunburn and permanent damage skin cells) and infrared (IR) of 700-1050 nm (i.e., risk of hyperthermia or dehydration in the infant during phototherapy). In order to overcome these negative effects, the light is filtered by inexpensive filters (specially-selected plastic window tinting film) to block potentially harmful UV wavelengths, attenuate IR wavelengths, while transmitting all but $\sim 20 \%$ of the therapeutic blue light $(400-520 \mathrm{~nm})$ for treating jaundiced neonates [79]. FSPT is inexpensive, does not require a stable electrical grid and is relatively easy to implement [80]. Compared with unfiltered radiation, blue light transmission through the plastic films has been shown to range from 24 to $83 \%$, ultraviolet A (UVA) transmission ranged from 0.1-7.1\%, and reductions in IR heat were $6-12{ }^{\circ} \mathrm{C}$ and $5-10^{\circ} \mathrm{C}$ for heat lamp and sun, respectively [79].

Results from three clinical studies conducted in Nigeria using FSPT have been published. In two studies conducted in Lagos, neonates were placed under an eight by eight-foot FSPT canopy and received treatment for neonatal jaundice. The mean irradiances of FSPT were $38 \pm 22$ (range: $2-115) \mu \mathrm{W} / \mathrm{cm}^{2} / \mathrm{nm}$ in the first study 
looking at safety and efficacy [81]. This study included 227 neonates and FSPT was shown to be both safe and efficacious. In the second study, FSPT was compared in a randomized controlled trial to conventional phototherapy. There were 224 infants under FSPT and 223 under conventional electric lamp phototherapy. The mean irradiance was $40 \pm 24$ (range $0-100 \mathrm{~W} / \mathrm{cm}^{2} / \mathrm{nm}$ as measured by the BiliBlanket Meter II [80]. FSPT was non-inferior to conventional phototherapy for treatment of jaundice in these infants. These initial studies appropriately included infants with mild to moderate jaundice. In both these studies no infant had to be withdrawn due to unsafe temperature deviations, sunburn or dehydration although those under FSPT did have mild temperature deviations which responded to simple measures such as wrapping infants in wet white towels briefly $[80,81]$.

In a third study, conducted in Ogbomoso, designed to simulate a rural setting and studying neonates with moderate-severe jaundice, FSPT was compared to intensive electric lamp phototherapy. FSPT was again shown to be safe and not inferior to intensive electric powered phototherapy [82]. The irradiance in the polycarbonate-covered phototherapy structures in this last study were 37.3 (interquartile range: $21.4-56.4) \mu \mathrm{W} /$ $\mathrm{cm}^{2} / \mathrm{nm}$. In this study the filters were placed under the clear polycarbonate roof panels in a well-ventilated clear polycarbonate-walled cabin-like structure $(2.4 \times$ $3.6 \times 2.4 \mathrm{~m}$ or $8 \times 12 \times 8 \mathrm{ft}$ ). Cabin ambient temperature was further minimalized through use of two solar powered stationary oscillating fans. In all three studies, efficacy was defined as rate of increase in TSB of $<0.2 \mathrm{mg} /$ $\mathrm{dL} / \mathrm{hr}$ for infants up to 72 hours of age and a decrease in TSB for infants older than 72 hours [80-82].

\section{Future Developments}

In an attempt to further improve the designs of FSPT canopies utilized in some of the aforementioned studies, the 450 Project team designed and constructed prototypes for both a large canopy (Sol Canopy, AGI, Greensburg, PA) that incorporates a $10-\mathrm{ft}$. by 15 -ft. plastic film over a framed structure and a smaller cradle (Sol Cradle, AGI, Greensburg, PA) to act as a portable FSPT unit [A. Gamber, unpublished report]. Although FSPT still requires additional testing and modifications, including a reliable way to monitor neonatal temperatures in rural areas with limited healthcare providers and facilities, it still has the potential to save lives and prevent KSD in areas without electricity and/or effective phototherapy.

In addition to introducing innovative technologies such as FSPT for treating neonatal hyperbilirubinemia, a package approach towards solving the clinical problem is being suggested such as: including education of both mothers [83] and healthcare providers; preventative strategies including components such as G6PD screening, avoidance of potential hemolytic triggers, Rhesus screening and low-cost anti-D immunoglobulin, blood group screening in mothers and their infants; better low-cost reliable diagnostics and further refinement of electric powered phototherapy and finally appropriate follow-up [84]. One notable success with a package approach, including many of the above components, was demonstrated in Myanmar, where investigators saw a 69\% reduction in exchange transfusions [85]. In another study, maternal education alone was shown to decrease ABE [86].

The reasons for inadequate hyperbilirubinemia treatment in low-income countries are extensive and multifaceted. However, in recent years, groups in high income countries have begun efforts to share their experience and partner with local health care workers who have extensive experience in the challenges they face to improve healthcare systems and to meet these challenges in their communities, focusing on neonatal jaundice $[33,50,68,85,87]$.

\section{Conclusions}

Neonatal hyperbilirubinemia presents a significant healthcare challenge in LMIC hospitals and communities and contributes to a significant percentage of overall childhood mortality all over the world. However, low-cost, effective, practical and reliable solutions exist that can be implemented. The hope is that by working in close partnership with our colleagues in LMICs to providing low-cost, safe, and efficacious technologies to those in need, combined with culturally appropriate medical- and educational interventions, people in LMICs will experience lower morbidity and mortality rates due to hyperbilirubinemia.

\section{Ethics Approval and Consent to Participate}

Not applicable.

\section{Consent for Publication}

Not applicable.

\section{Availability of Data and Materials}

Not applicable.

\section{Competing Interests}

This study was funded by Asset Genie Inc. None of the authors declare competing interests.

\section{Funding}

Adam Gamber and Ethan Toth's contributions were performed as part of their employment of Asset Genie Inc which also provided funding for some of the editing and formatting of this manuscript.

\section{Acknowledgements}

The authors thank the International Medical Corps for their valuable cooperation, the University of Gondar Pediatrics Department (Gondar, Ethiopia) for its information on healthcare in developing regions, and John Mahoney for valuable editorial assistance towards editing and reformatting the manuscript. 


\section{References}

1. Dysart KC (2018) Neonatal hyperbilirubinemia (jaundice in neonates). Merck Manual.

2. National Institute for Health and Care Excellence (NICE) (2010) Clinical guideline 98 - Neonatal jaundice. Royal College of Obstetricians and Gynaecologists, London.

3. Greco C, Arnolda G, Boo N-Y, Iskander IF, Okolo AA, et al. (2016) Neonatal jaundice in low- and middle-income countries: Lessons and future directions from the 2015 Don Ostrow Trieste Yellow Retreat. Neonatology 110: 172-180.

4. Slusher TM, Zamora TG, Appiah D, Stanke JU, Strand MA, et al. (2017) Burden of severe neonatal jaundice: A systematic review and meta-analysis. BMJ Paediatr Open 1: e000105.

5. Bhutani VK, Zipursky A, Blencowe H, Khanna R, Sgro M, et al. (2013) Neonatal hyperbilirubinemia and Rhesus disease of the newborn: Incidence and impairment estimates for 2010 at regional and global levels. Pediatr Res 74: 86-100.

6. Pichon JB, Riordan SM, Watchko J, Shapiro SM (2017) The neurological sequelae of neonatal hyperbilirubinemia: Definitions, diagnosis and treatment of the kernicterus spectrum disorders (KSDs). Curr Pediatr Rev 13: 199-209.

7. Dennery PA, Seidman DS, Stevenson DK (2001) Neonatal hyperbilirubinemia. N Eng J Med 344: 581-590.

8. Ullah S, Rahman K, Hedayati M (2016) Hyperbilirubinemia in neonates: Types, causes, clinical examinations, preventive measures and treatments: A narrative review article. Iran J Public Health 45: 558-568.

9. Strauss KA, Robinson DL, Vreman HJ, Puffenberger EG, Hart G, et al. (2006) Management of hyperbilirubinemia and prevention of kernicterus in 20 patients with Crigler-Najjar disease. Eur J Pediatr 165: 306-319.

10. Ip S, Chung M, Kulig J, O'Brien R, Sege R, et al. (2004) An evidence-based review of important issues concerning neonatal hyperbilirubinemia. Pediatrics 114: e130-e153.

11. Gomella TL, Cunningham MD, Eyal FG, Tuttle D (2013) Neonatology: Management, procedures, on-call problems, diseases, and drugs. ( $7^{\text {th }}$ edn), McGraw-Hill Education, New York, USA.

12. Maisels MJ (2006) Neonatal jaundice. Pediatr Rev 27: 443454.

13. Maisels MJ (2006) What's in a name? Physiologic and pathologic jaundice: The conundrum of defining normal bilirubin levels in the newborn. Pediatrics 118: 805-807.

14. Maisels MJ, Newman TB (1995) Kernicterus in otherwise healthy, breast-fed term newborns. Pediatrics 96: 730-733.

15. Brahm P, Valdés $V$ (2017) The benefits of breastfeeding and associated risks of replacement with baby formulas. Rev Chil Pediatr 88: 7-14.

16. Bratton S, Cantu RM, Stern M (2020) Breast milk jaundice. In: StatPearls [Internet]. StatPearls, Treasure Island (FL).

17. American Academy of Pediatrics Subcommittee on Hyperbilirubinemia (2004) Management of hyperbilirubinemia in the newborn infant 35 or more weeks of gestation. Pediatrics 114: 297-316.

18. Olusanya BO, Ogunlesi TA, Kumar P, Boo N-Y, Iskander IF, et al. (2015) Management of late-preterm and term infants with hyperbilirubinaemia in resource-constrained settings. BMC Pediatr 15: 39.

19. Moyer VA, Ahn C, Sneed S (2000) Accuracy of clinical judgment in neonatal jaundice. Arch Pediatr Adolesc Med 154: 391-394.

20. Webster J (2006) An appraisal of the use of the Kramer's scale in predicting hyperbilirubinaemia in healthy full term infants. Birth issues 14: 83-89.

21. Tikmani SS, Warraich HJ, Abbasi F, Rizvi A, Darmstadt GL, et al. (2010) Incidence of neonatal hyperbilirubinemia: A population-based prospective study in Pakistan. Trop Med Int Health 15: 502-507.

22. Usman F, Diala UM, Shapiro SM, Le Pichon JB, Slusher TM (2018) Acute bilirubin encephalopathy and its progression to kernicterus: Current perspectives. Research and Reports in Neonatology 8: 33-44.

23. Ahlfors CE, Wennberg RP, Ostrow JD, Tiribelli C (2009) Unbound (free) bilirubin: Improving the paradigm for evaluating neonatal jaundice. Clin Chem 55: 1288-1299.

24. Slusher TM, Angyo IA, Bode-Thomas F, Akor F, Pam SD, et al. (2004) Transcutaneous bilirubin measurements and serum total bilirubin levels in indigenous African infants. Pediatrics 113: 1636-1641.

25. Kaplan M, Bromiker R (2019) Variation in transcutaneous bilirubin nomograms across population groups. J Pediatr 208: 273-278.

26. Seyedi R, Mirghafourvand M, Dost AJ, Mohammad-Alizadeh-Charandabi S, Jafarabadi MA, et al. (2019) Transcutaneous bilirubin nomogram for evaluating the risk of hyperbilirubinemia in Iranian healthy newborns. World $\mathrm{J}$ Pediatr 15: 72-77.

27. Lee AC, Folger LV, Rahman M, Ahmed S, Bably NN, et al. (2019) A novel Icterometer for hyperbilirubinemia screening in low-resource settings. Pediatrics 143: e20182039.

28. Olusanya BO, Mabogunje CA, Imosemi DO, Emokpae AA (2017) Transcutaneous bilirubin nomograms in African neonates. PLoS One 12: e0172058.

29. Olusanya BO, Ogunlesi TA, Slusher TM (2014) Why is kernicterus still a major cause of death and disability in low-income and middle-income countries? Arch Dis Child 99: 1117-1121.

30. Hansen TWR, Maisels MJ, Ebbesen F, Vreman HJ, Stevenson DK, et al. (2020) Sixty years of phototherapy for neonatal jaundice-from serendipitous observation to standardized treatment and rescue for millions. J Perinatol 40: 180-193.

31. Ebbesen F, Rodrigo-Domingo M, Moeller AM, Vreman HJ, Donneborg ML, et al. (2019) Effect of blue LED phototherapy centered at $478 \mathrm{~nm}$ versus $459 \mathrm{~nm}$ in hyperbilirubinemic neonates: a randomized study. Pediatr. Res. 2020 Apr 26. doi: 10.1038/s41390-020-0911-9 Online ahead of print.

32. Maisels MJ, McDonagh AF (2008) Phototherapy for neonatal jaundice. N Eng J Med 358: 920-928.

33. Bhutani VK, Meng NF, Knauer Y, Danielsen BH, Wong RJ, et al. (2016) Extreme hyperbilirubinemia and rescue exchange transfusion in California from 2007 to 2012. J Perinatol 36: 853-857.

34. Diala UM, Ofakunrin AO, Toma BO, Shwe DD, Yilgwan CS, et al. (2018) Factors influencing irradiance of locally fabricated phototherapy devices in Jos, north-central Nigeria. Trop Doct 48: 142-146.

35. Cline BK, Vreman HJ, Faber K, Lou H, Donaldson KM, et al. (2013) Phototherapy device effectiveness in Nigeria: Irradiance assessment and potential for improvement. J Trop Pediatr 59: 321-325. 
36. Satrom K, Slusher T, Satrom J (2014) Effectiveness of phototherapy units in Cameroon. J Trop Pediatr 60: 264-246.

37. Pejaver RK, Vishwanath J (2000) An audit of phototherapy units. Indian J Pediatr 67: 883-834.

38. Olusanya BO, Osibanjo FB, Slusher TM (2015) Risk factors for severe neonatal hyperbilirubinemia in low and middle-income countries: A systematic review and meta-analysis. PLoS One 10: e0117229.

39. Bujandric N, Grujic J (2016) Exchange transfusion for severe neonatal hyperbilirubinemia: 17 years' experience from Vojvodina, Serbia. Indian J Hematol Blood Transfus 32: 208-214.

40. Jackson JC (1997) Adverse events associated with exchange transfusion in healthy and ill newborns. Pediatrics 99: E7.

41. Chacham S, Kumar J, Dutta S, Kumar P (2019) Adverse events following blood exchange transfusion for neonatal hyperbilirubinemia: A prospective study. J Clin Neonatol 8: 79-84.

42. Sabzehei MK, Basiri B, Shokouhi M, Torabian S (2015) Complications of exchange transfusion in hospitalized neonates in two neonatal centers in Hamadan, a five-year experience. J Compr Ped 6: e20587.

43. Olusanya BO, Teeple S, Kassebaum NJ (2018) The contribution of neonatal jaundice to global child mortality: Findings from the GBD 2016 study. Pediatrics 141: e20171471.

44. Mills A (2014) Health care systems in low-and middle-income countries. N Eng J Med 370: 552-557.

45. Keahey P, Simeral M, Schroder K, Bond M, Mtenthaonnga $\mathrm{P}$, et al. (2019) Low-cost diagnostic for monitoring neonatal jaundice in low-resource settings (Conference Presentation). Proc. SPIE 10885, Optical Diagnostics and Sensing XIX: Toward Point-of-Care Diagnostics, 108850M.

46. Johnson L, Brown AK, Bhutani VK (1999) BIND-a clinical score for bilirubin induced neurologic dysfunction in newborns. Pediatrics 199: 746-747.

47. Ogunfowora OB, Daniel OJ (2006) Neonatal jaundice and its management: Knowledge, attitude and practice of community health workers in Nigeria. BMC Public Health 6: 19.

48. Okperi BO (2013) Neonatal jaundice and birth asphyxia as major causes of cerebral palsy in Nigeria: Are doctors' wrong beliefs and practices part of the problem? Int J Med Biomed Res 2: 226-230.

49. Slusher TM, Zipursky A, Bhutani VK (2011) A global need for affordable neonatal jaundice technologies. Semin Perinatol 35: 185-191.

50. Diala UM, Wennberg RP, Abdulkadir I, Farouk ZL, Zabetta CDC, et al. (2018) Patterns of acute bilirubin encephalopathy in Nigeria: A multicenter pre-intervention study. J Perinatol 38: 873-880.

51. Olusanya BO, Osibanjo FB, Mabogunje CA, Slusher TM, Olowe SA (2016) The burden and management of neonatal jaundice in Nigeria: A scoping review of the literature. Niger J Clin Pract 19: 1-17.

52. Ayanniyi O, Abdulsalam KS (2015) Profile of children with cerebral palsy attending out-patient physiotherapy clinics in Southwest Nigeria. AJPARS 7: 32-39.

53. Gordon AL, English M, Dzombo JT, Karisa M, Newton CRJC (2005) Neurological and developmental outcome of neonatal jaundice and sepsis in rural Kenya. Trop Med Int Health 10: 1114-1120.
54. Olusanya BO, Okolo AA (2006) Adverse perinatal conditions in hearing-impaired children in a developing country. Paediatr Perinat Epidemiol 20: 366-371.

55. Amin SB, Saluja S, Saili A, Laroia N, Orlando M, et al. (2017) Auditory toxicity in late preterm and term neonates with severe jaundice. Dev Med Child Neurol 59: 297-303.

56. Farouk ZL, Muhammed A, Gambo S, Mukhtar-Yola M, Abdullahi SU, et al. (2018) Follow-up of children with kernicterus in Kano, Nigeria. J Trop Pediatr 64: 176-182.

57. Osuorah CD, Ekwochi U, Asinobi IN (2018) Clinical evaluation of severe neonatal hyperbilirubinaemia in a resource-limited setting: A 4-year longitudinal study in southEast Nigeria. BMC Pediatr 18: 202.

58. McDonagh AF (2001) Phototherapy: From ancient Egypt to the new millennium. J Perinatol 21: S7-S12.

59. Vreman HJ, Wong RJ, Murdock JR, Stevenson DK (2008) Standardized bench method for evaluating the efficacy of phototherapy devices. Acta Paediatr 97: 308-316.

60. Mohammadizadeh M, Eliadarani FK, Badiei Z (2012) Is the light-emitting diode a better light source than fluorescent tube for phototherapy of neonatal jaundice in preterm infants? Adv Biomed Res 1: 51.

61. Nakamura S, Senoh M, Iwasa N, Nagahama SI (1995) High-brightness InGaN blue, green and yellow light-emitting diodes with quantum well structures. Jap J Appl Phys 34: L797-L799.

62. Nakamura S, Pearton S, Fasol G (2000) The blue laser diode: The complete story. Springer Science \& Business Media 28.

63. Comstock O, Jarzomski K (2014) LED bulb efficiency expected to continue improving as cost declines. U.S. Energy Information Administration.

64. Vreman HJ, Wong RJ, Stevenson DK (2004) Phototherapy: Current methods and future directions. Semin Perinatol 28: 326-333.

65. Stokowski LA (2011) Fundamentals of phototherapy for neonatal jaundice. Adv Neonat Care11: S10-S21.

66. Olusanya BO, Osibanjo FB, Emokpae AA, Slusher TM (2016) Irradiance decay in fluorescent and light-emitting diode-based phototherapy devices: A pilot study. J Trop Pediatr 62: 421-424.

67. Gutta S, Shenoy J, Kamath SP, Mithra P, Baliga BS, et al. (2019) Light Emitting Diode (LED) phototherapy versus conventional phototherapy in neonatal hyperbilirubinemia: A single blinded randomized control trial from Coastal India. BioMed Res Int 2019: 6274719.

68. Abdulkadir I, Lawal S, Adebiyi MN, Vreman HJ, Slusher TM (2019) Making locally fabricated phototherapy devices work better. J Trop Pediatr 66: 24-28.

69. Olusanya BO, Iskander IF, Slusher TM, Wennberg RP (2016) A decision-making tool for exchange transfusions in infants with severe hyperbilirubinemia in resource-limited settings. J Perinatol 36: 338-341.

70. Keahey PA, Simeral ML, Schroder KJ, Bond MM, Mtenthaonnga PJ, et al. (2017) Point-of-care device to diagnose and monitor neonatal jaundice in low-resource settings. Proc Natl Acad Sci U S A 114: E10965-E10971.

71. (2019) Little Sparrows Technologies, Somerville, MA, United States.

72. INMED. Neonatal jaundice: A transformational approach to neonatal jaundice. 
73. D-Rev Projects: Neonate Health.

74. Firefly, Design that Matters ${ }^{\mathrm{TM}}$.

75. Tiny Hearts, Kpansia, Yenagoa Balyelsa, Nigeria.

76. Cremer RJ, Lond MB, Perryman PW, Richards DH (1958) Influence of light on the hyperbilirubinemia of infants. Lancet 271: 1094-1097.

77. Salih FM (2001) Can sunlight replace phototherapy units in the treatment of neonatal jaundice? An in vitro study. Photodermatol Photoimmunol Photomed 17: 272-277.

78. Olowe SA (1985) Sunshine phototherapy cot: Utilization of sunlight for phototherapy. Niger J Paediatr 12: 69-70.

79. Vreman HJ, Slusher TM, Wong RJ, Schulz S, Olusanya BO, et al. (2013) Evaluation of window-tinting films for sunlight phototherapy. J Trop Pediatr 59: 496-501.

80. Slusher TM, Olusanya BO, Vreman HJ, Brearly AM, Vaucher YE, et al. (2015) A randomized trial of phototherapy with filtered sunlight in African neonates. N Eng J Med 373: 1115-1124.

81. Slusher TM, Vreman HJ, Olusanya BO, Wong RJ, Brearly AM, et al. (2014) Safety and efficacy of filtered sunlight in treatment of jaundice in African neonates. Pediatrics 133: e1568-e1574.

82. Slusher TM, Vreman HJ, Brearley AM, Vaucher YE, Wong RJ, et al. (2018) Filtered sunlight versus intensive electric powered phototherapy in moderate-to-severe neonatal hyperbilirubinemia: A randomised controlled non-inferiority trial. Lancet Glob Health 6: e1122-e1131.

83. Abdulkadir I, Adeoye G, Adebiyi MN, Hassan L, Abdullahi FL, et al. (2018) Influence of maternal educational instruction on mothers' knowledge about neonatal jaundice. Niger J Basic Clin Sci 15: 37-41.

84. Slusher TM, Day LT, Ogundele T, Woolfield N, Owa JA (2017) Filtered sunlight, solar powered phototherapy and other strategies for managing neonatal jaundice in low-resource settings. Early Hum Dev 114: 11-15.

85. Arnolda G, Thein AA, Trevisanuto D, Aung N, Nwe HM, et al. (2015) Evaluation of a simple intervention to reduce exchange transfusion rates among inborn and outborn neonates in Myanmar, comparing pre-and post-intervention rates. BMC Pediatr 15: 216.

86. Zainab I, Farouk Z, Abdulkadir I, Ofakunrin A, Slusher T, et al. (2016) Empowering mothers prevents kernicterus in Nigeria. Pediatric Academic Societies Annual Meeting, Baltimore. PAS 2016: 2365.7. Abstract number 750558.

87. Greco C, Iskander IF, El Houchi SZ, Rohsiswatmo R, Rundjan L, et al. (2018) Diagnostic performance analysis of the point-of-care Bilistick System in identifying severe neonatal hyperbilirubinemia by a multi-country approach. EClinicalMedicine 1: 14-20. 